\title{
Effects of mannan oligosaccharide and Curcuma xanthorrhiza essential oil on the intestinal morphologyand stress indicators of broilers subjected to cyclic heat stress
}

\author{
Seyed Mohammad Hosseini ${ }^{1}$, Hasan Nazarizadeh ${ }^{1}$, Saeede Ahani ${ }^{2}$, and Masoume Vakili Azghandi ${ }^{2}$ \\ ${ }^{1}$ Department of Animal Science, University of Birjand, Birjand, Iran \\ ${ }^{2}$ Young Researchers \& Elites Club, Birjand Branch, Islamic Azad University, Birjand, Iran
}

Correspondence to: Masoume Vakili Azghandi (m.vakili2009@gmail.com)

Received: 7 February 2016 - Revised: 15 May 2016 - Accepted: 30 May 2016 - Published: 17 June 2016

\begin{abstract}
An experiment was carried out that was intended to explore the growth performance, nutrient retention, and heat stress biomarkers of finishing broilers under cyclic heat stress (HS) as modulated by the supplementation of mannan oligosaccharide (MOS) and Curcuma xanthorrhiza essential oil (CXEO). Two hundred and forty 21-day-old Ross 308 male broilers were allocated to four experimental treatments, each of which was replicated six times with 10 broilers per replicate. The diets included a control $(\mathrm{CON}), \mathrm{CON}+5 \mathrm{~g}$ of $\mathrm{MOS} \mathrm{kg}^{-1}$,

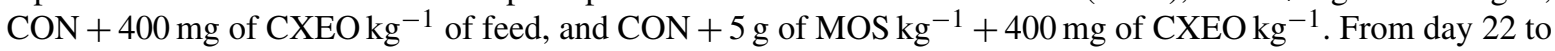
42 , birds were subjected to cyclic HS by exposing them to $33^{\circ} \mathrm{C}$ for $10 \mathrm{~h}$ (from 07:00 to 17:00 LT) and $22^{\circ} \mathrm{C}$ from 17:00 to 07:00. Dietary treatments did not have an effect on average daily feed intake, feed conversion ratio, the duodenal histomorphology, and relative visceral weights. Body weight, average daily gain, villus length, crypt depth, and the villus-length-to-crypt-depth ratio in the jejunum were significantly increased in birds fed MOS or MOS + CXEO diets $(p<0.05)$. The relative bursa weight of the control birds was lower $(p<0.05)$ compared to those fed the MOS diet. Compared with CON, dietary treatments reduced corticosterone and creatine kinase levels, the heterophile-to-lymphocyte ratio, and mRNA levels of heat shock protein 70 in the breast muscle and jejunum $(p<0.05)$. It was concluded that dietary supplementation of either MOS or CXEO alone or in combination may reduce some of the harmful effects of HS in broiler chickens.
\end{abstract}

\section{Introduction}

The effect of a high environmental temperature during some months of the year on broiler production has been a great problem in many countries. In the east of Iran, maximum ambient temperatures of $35-42{ }^{\circ} \mathrm{C}$ during the months of May to September are normal and the performance of birds is reduced dramatically (Akbarian et al., 2014). Heat stress (HS) is known to lead to a reduction in feed intake, a decrease in body weight, a high mortality rate (Yahav et al., 1995), and immunosuppression (May et al., 1986) in broiler chickens. Several indexes are measured as stress biomarkers in broilers, including plasma corticosterone (CS), cholesterol, glucose, the heterophil-to-lymphocyte $(\mathrm{H}: \mathrm{L})$ ratio, the rela- tive weights of spleen and bursa, and heat shock protein expression in skeletal and cardiac muscles (Buijs et al., 2009). Heat stress affects the birds' response to different feed additives, such as prebiotics and herbal essential oils (Patterson and Burkholder, 2003). Recent research has focused on the role of prebiotics and phytobiotics as functional foods to influence productive performance, immunity, intestinal morphology, and gut microbiota. More recently, these feed additives have been fed as supplements to broiler chickens under HS (Sohail et al., 2012; Akbarian et al., 2014). Because of the positive effects of prebiotics on microbiota, it is possible that dietary supplementation with prebiotics can help the birds overcome any performance deficiency and simultaneously increase their tolerance of HS (Ghareeb et al., 2008). 
Sohail et al. (2010) found that dietary supplementation with mannan oligosaccharide (MOS) decreased some negative effects of HS in finishing broiler chickens.

Curcuma xanthorrhiza (CX), known as Temulawak, is native to tropical Asia and is used as a medicinal plant. The CX essential oil (CXEO) contains high amounts of phenols, and its antioxidant activity is well detected (Luna et al., 2010). The antioxidant activity of CXEO mainly refers to xanthorrhizol, ar-curcumene, and $\beta$-curcumene. It has been well documented that using plant extracts rich in phenolic compounds could positively affect gut health and metabolism parameters of heat-challenged broilers (Akbarian et al., 2013). The positive effect of curcuma or its essential oil on the immunity of broilers has already been reported (Avila-Ramos et al., 2012).

To the best of our knowledge, the supplemental effects of MOS and CXEO on broilers reared under cyclic HS are largely unknown. Thus, this study was set up to investigate the effects of MOS and CXEO on growth performance, intestinal morphology, and biomarker indicators of broilers subjected to cyclic HS.

\section{Materials and methods}

\subsection{Birds and diets}

Two hundred and forty 21-day-old (710 $\pm 1.0 \mathrm{~g}$, Ross 308) male broiler chickens were randomly divided into four dietary treatments with six replicates $(n=10$ in each replicate). The chicks were raised up to 21 days of age on a basal diet (crude protein (CP), $22 \%$ and metabolizable energy (ME), $12.98 \mathrm{MJ} \mathrm{kg}^{-1}$ ). A corn-soybean-meal-based diet was formulated to meet all nutrient recommendations published in the Ross rearing guideline (Aviagen ${ }^{\circledR}, 2011$; Table 1). From day 22 until the end of the trial (day 42), four experimental diets were fed to six replicate pens in a completely randomized design. The four dietary treatments were as follows: control diet (CON; basal diet, without additives), $\mathrm{CON}+0.5 \%$ MOS (MOS; Bio-Mos, Alltech, Nicholasville, $\mathrm{KY}$ ), $\mathrm{CON}+400 \mathrm{mg}$ of $\mathrm{CXEO} \mathrm{k^{-1 }}$ of feed, and a combination of both additives (MOS + CXEO). Bio-Mos is a commercial mannan oligosaccharide (MOS) derived from the outer layer of the yeast (Saccharomyces cerevisiae) cell wall. The CXEO was obtained from Phytochemindo Reska. PT (Bogor, Indonesia). According to the compositional data provided by the supplier, the main bioactive compounds were ar-curcumene $(24.5 \%), \beta$-curcumene $(24.4 \%)$, xanthorrhizol $(20.3 \%)$, and curcumin $(0.25 \%)$. In the experiment period, birds were subjected to cyclic heat stress by exposing them to $33^{\circ} \mathrm{C}$ for $10 \mathrm{~h}$, from 07:00 to $17: 00 \mathrm{LT}$ daily, and $22^{\circ} \mathrm{C}$ from $17: 00$ to $07: 00$ daily. The lighting program was 23L:1D during the entire period. Air humidity was kept at 60-65\% throughout the experimental period. The birds were reared in pens $(90 \times 120 \times 70 \mathrm{~cm}$, length $\times$ width $\times$ height $)$ and given ad libitum access to feed and water. The animal
Table 1. Ingredients and calculated composition of the basal diet.

\begin{tabular}{lr}
\hline Item & Amount in basal diet \\
\hline Ingredient, $\mathrm{g} \mathrm{kg}^{-1}$ & \\
\hline Corn, $8 \% \mathrm{CP}$ & 573.4 \\
Soybean meal, $48 \% \mathrm{CP}$ & 300.4 \\
Fish meal & 30.0 \\
Palm oil & 63.4 \\
Dicalcium phosphate & 10.0 \\
Limestone & 11.6 \\
Salt & 2.9 \\
Lysine hydrochloride & 0.6 \\
DL-methionine & 1.7 \\
Vitamin premix & 2.5 \\
Mineral premix & \\
Choline chloride & 2.5 \\
\hline Calculated Analysis & 1.0 \\
\hline Metabolizable energy $\left(\mathrm{MJ} \mathrm{kg}^{-1}\right)$ & 13.4 \\
Available phosphorus $\left(\mathrm{g} \mathrm{kg}^{-1}\right)$ & 4.5 \\
Lysine $\left(\mathrm{g} \mathrm{kg}{ }^{-1}\right)$ & 10.0 \\
Methionine $\left(\mathrm{g} \mathrm{kg}^{-1}\right)$ & 3.8 \\
\hline Calculated composition, $\mathrm{g} \mathrm{kg}^{-1}$ & 200 \\
Crude protein $(N \times 6.25)$ & 9.3 \\
Calcium & 60.0 \\
Available phosphorus & 30.0 \\
Crude fat & \\
\hline Crude fiber & \\
\hline
\end{tabular}

${ }^{1}$ The vitamin premix supplied the following per kilogram of diet: vitamin A (retinyl acetate), $8000 \mathrm{IU}$; vitamin D3, $1000 \mathrm{IU}$; vitamin E (dl- $\alpha$-tocopherol), $30 \mathrm{IU}$; vitamin $\mathrm{K} 3,2.5 \mathrm{mg}$; vitamin B1, $2 \mathrm{mg}$; vitamin B2, $5 \mathrm{mg}$; vitamin B6,

$2 \mathrm{mg}$; vitamin B12, $0.01 \mathrm{mg}$; niacin, $30 \mathrm{mg}$; d-biotin, $0.045 \mathrm{mg}$; vitamin C,

$50 \mathrm{mg}$; d-pantothenate, $8 \mathrm{mg}$, folic acid, $0.5 \mathrm{mg}$. ${ }^{2}$ The mineral premix supplied the following per kilogram of diet: $\mathrm{Mn}, 70 \mathrm{mg} ; \mathrm{Fe}, 35 \mathrm{mg} ; \mathrm{Zn}$,

$70 \mathrm{mg} ; \mathrm{Cu}, 8 \mathrm{mg} ; \mathrm{I}, 1 \mathrm{mg}, \mathrm{Se}, 0.25 \mathrm{mg} ; \mathrm{Co}, 0.2 \mathrm{mg}$.

care protocol in this experiment was approved by the Animal Ethics Committee of the University of Birjand.

\subsection{Growth performance}

Considering the pen as the experimental unit, body weight (BW) and feed intake were recorded weekly. The data were used to calculate $\mathrm{BW}$ gain (BWG), average daily gain (ADG), average daily feed intake (ADFI), and feedconversion ratio (FCR) for 22 to 42 days of age. The mortality rate was recorded upon occurrence.

\subsection{Size of different organs}

On day 42 ( 3 weeks after starting the heat challenge, end of experiment), two birds were randomly sampled from each pen (12 birds per treatment) and slaughtered by cutting the jugular veins and carotid arteries; they were processed manually and collections were made following a $4 \mathrm{~h}$ fast. The weights of the pancreas, liver, heart, gizzard, intestine, 
Table 2. Effect of mannan oligosaccharide (MOS) and Curcuma xanthorrhiza essential oil (CXEO) on the growth performance of finishing broilers subjected to heat challenge.

\begin{tabular}{lrrrrrr}
\hline Item & \multicolumn{4}{c}{ Treatments $^{1}$} & \multirow{2}{*}{ SEM } & $P$ value \\
\cline { 2 - 5 } & Control & MOS & CXEO & MOS + CXEO & & \\
\hline BW gain at 42 days, g & $1859^{\mathrm{b}}$ & $1951^{\mathrm{a}}$ & $1865^{\mathrm{b}}$ & $1960^{\mathrm{a}}$ & 12.3 & 0.03 \\
Average daily gain, g & $55.9^{\mathrm{b}}$ & $60.3^{\mathrm{a}}$ & $56.2^{\mathrm{b}}$ & $60.7^{\mathrm{a}}$ & 0.2 & 0.04 \\
Average daily feed intake, g & 114.5 & 115.1 & 114.7 & 115.4 & 1.2 & 0.17 \\
Feed conversion ratio, g g & $2.05^{\mathrm{a}}$ & $1.91^{\mathrm{b}}$ & $2.04^{\mathrm{a}}$ & $1.90^{\mathrm{b}}$ & 0.02 & 0.02 \\
\hline
\end{tabular}

a-b Mean values within a line with no common superscript differ significantly from each other $(P<0.05)$. Each value represents the mean of 12 observations (six replicates $\times$ two birds / replicate). ${ }^{1}$ The control group was fed no additive. Other groups were fed $5 \mathrm{~g} \mathrm{~kg}^{-1}$ of MOS (MOS), $400 \mathrm{mg} \mathrm{kg}^{-1}$ of CXEO (CXEO), or $5 \mathrm{~g} \mathrm{~kg}^{-1}$ of MOS $+400 \mathrm{mg} \mathrm{kg}^{-1}$ of CXEO (MOS + CXEO).

spleen, and bursa were recorded. Their relative weights (ratio of weight to final BW) were used for statistical analysis.

\subsection{Biomarker analysis}

For the analysis of the HS biomarkers including circulating cholesterol $(\mathrm{CHO})$, corticosterone (CS), creatine kinase (CK), heterophil $(\mathrm{H})$, lymphocyte $(\mathrm{L})$, and the $\mathrm{H}: \mathrm{L}$ ratio, blood samples were collected $(2 \mathrm{~mL})$ from 12 broilers per treatment (the same broilers that were slaughtered), put in tubes containing heparin as the anticoagulant (Fisher Health Care, Houston, TX), and kept on ice and immediately used for hematological analysis. Attention was paid to warrant that the time between catching the bird and obtaining the blood samples did not exceed $40 \mathrm{~s}$. Plasma CHO level was determined using an automated chemistry analyzer (Hitachi 902 Automatic Analyzer, Hitachi, Tokyo, Japan). Plasma CS concentration was measured by the Enzyme-Linked Immunosorbent Assay (ELISA) method described by De Jong et al. (2001). Hematological analysis was conducted to measure the levels of lymphocytes and heterophiles by using an automatic hematological analyzer (XE-2100, Automated Hematology Analyzer, Sysmex America, Inc.). Values of lymphocyte and heterophile counts were also used to calculate the $\mathrm{H}: \mathrm{L}$ ratio.

\section{mRNA expression analysis}

The chicken breast samples (without skin and adipose tissue) from same killed birds were collected and frozen in liquid nitrogen; they were then used to analyze the HS biomarkers, including levels of $\mathrm{CK}$ and relative values of HSP70 mRNA expression in breast muscle. The jejunum samples were also cut into small pieces and homogenized. The HSP7O mRNA levels in breast muscle and jejunum samples were analyzed by quantitative real-time polymerase chain reaction (PCR; Hao et al., 2012). The total RNA concentration was extracted using Trizol reagent (Invitrogen, Carlsbad, CA) per the manufacturer's instructions. One microgram of the total RNA was reverse-transcribed to complementary DNA by using a SuperScript III Reverse
Transcriptase kit (Invitrogen). The HSP70 was amplified in the ABI SYBR Green PCR Master Mix (Applied Biosystems, Foster City, CA) from the complementary DNA with specific primers. The chicken $H S P 70$ gene sequence deposited in GenBank under the accession number J02579 was used as nucleotide sequence in the current research. The quantitative real-time PCR primer was used in this study as follows: HSP70 (GenBank NM001006685) forward $5^{\prime}$-CGTCAGTGCTGTGGACAAGAGTA-3', reverse 5'-CCTATCTCTGTTGGCTTCATCCT-3'. Amplification was initiated by 2 and $5 \mathrm{~min}$ incubation periods at 50 and $95^{\circ} \mathrm{C}$, respectively, followed by 40 cycles at $95^{\circ} \mathrm{C}$ for $10 \mathrm{~s}$ and $60^{\circ} \mathrm{C}$ for $30 \mathrm{~s}$. Relative standard curves were obtained by plotting the cycle threshold $(\mathrm{Ct})$ obtained after PCR amplification of serial dilutions of a steady quantity of a plasmid containing the corresponding complementary DNA.

\subsection{Intestinal morphology}

Intestinal fragments of approximately $2 \mathrm{~cm}$ in length of the duodenum and jejunum were excised and flushed with 0.9 saline to remove the contents. These samples were kept in $10 \%$ neutral buffered formalin at $4{ }^{\circ} \mathrm{C}$ for fixation until morphometric analysis. The segments of the small intestine collected were the loop of the duodenum and the midpoint between the bile duct entry and Meckel's diverticulum. The villus length (from the tip of the villus to crypt), crypt depth (from the base of the villi to the submucosa), and the villus-length-to-crypt-depth ratio were measured (Zhang et al., 2009).

\subsection{Statistical analysis}

Data were analyzed by analysis of variance (ANOVA) using the general linear model (GLM) procedure of SAS (SAS Institute Inc., NC, USA). A Tukey test was used to make pairwise comparisons among means, and differences between treatments were considered significant at $P<0.05$. 
Table 3. Effect of mannan oligosaccharide (MOS) and Curcuma xanthorrhiza essential oil (CXEO) on relative organ weight in broilers subjected to heat challenge. SEM: standard error of the mean.

\begin{tabular}{lrrrrrr}
\hline \multirow{2}{*}{ Item } & \multicolumn{5}{c}{ Treatments $^{\text {SEM }}$} & \multirow{2}{*}{$P$ value } \\
\cline { 2 - 5 } & Control & MOS & CXEO & MOS + CXEO & \\
\hline Pancreas & 0.25 & 0.26 & 0.23 & 0.22 & 0.00 & 0.87 \\
Liver & 2.51 & 2.53 & 2.50 & 2.52 & 0.02 & 0.16 \\
Heart & 0.46 & 0.45 & 0.44 & 0.47 & 0.01 & 0.12 \\
Gizzard & 1.41 & 1.38 & 1.40 & 1.42 & 0.01 & 0.26 \\
Intestine & 2.62 & 2.73 & 2.66 & 2.69 & 0.13 & 0.18 \\
Spleen & 0.15 & 0.16 & 0.14 & 0.15 & 0.00 & 0.04 \\
Bursa & $0.15^{\mathrm{b}}$ & $0.19^{\mathrm{a}}$ & $0.16^{\mathrm{ab}}$ & $0.17^{\mathrm{ab}}$ & 0.01 & 0.03 \\
\hline
\end{tabular}

a-b Mean values within a line with no common superscript differ significantly from each other $(P<0.05)$. Each value represents the mean of 12 observations (six replicates $\times$ two birds $/$ replicate).

${ }^{1}$ The control group was fed no additive. Other groups were fed $5 \mathrm{~g} \mathrm{~kg}^{-1}$ of MOS (MOS), $400 \mathrm{mg} \mathrm{kg}^{-1}$ of CXEO (CXEO), $5 \mathrm{~g} \mathrm{~kg}^{-1}$ of MOS $+400 \mathrm{mg} \mathrm{kg}^{-1}$ of CXEO (MOS + CXEO) or $400 \mathrm{mg} \mathrm{kg}^{-1}$ of CXEO (CXEO), or $5 \mathrm{~g} \mathrm{~kg}^{-1}$ of MOS $+400 \mathrm{mg} \mathrm{kg}^{-1}$ of CXEO (MOS + CXEO), respectively.

Table 4. Effect of mannan oligosaccharide (MOS) and Curcuma xanthorrhiza essential oil (CXEO) on stress indicators in broilers subjected to heat challenge.

\begin{tabular}{|c|c|c|c|c|c|c|}
\hline \multirow[t]{2}{*}{ Item } & \multicolumn{4}{|c|}{ Treatments 1} & \multirow[t]{2}{*}{ SEM } & \multirow[t]{2}{*}{$P$ value } \\
\hline & Control & MOS & CXEO & $\mathrm{MOS}+\mathrm{CXEO}$ & & \\
\hline Cholesterol, $\mathrm{mmol} \mathrm{L}^{-1}$ & 3.2 & 3.3 & 2.9 & 3.0 & 0.07 & 0.09 \\
\hline Corticosterone, $\mathrm{pg} \mathrm{mL}^{-1}$ & $275.3^{\mathrm{a}}$ & $112.8^{\mathrm{b}}$ & $96.7^{\mathrm{b}}$ & $95.4^{\mathrm{b}}$ & 2.46 & 0.01 \\
\hline Heterophiles $\left(\mathrm{H} ; \times 10^{9} \mathrm{~L}^{-1}\right)$ & 35.5 & 34.0 & 33.1 & 33.2 & 0.4 & 0.46 \\
\hline Lymphocytes $\left(\mathrm{L} ; \times 10^{9} \mathrm{~L}^{-1}\right)$ & 103.1 & 106.3 & 108.2 & 107.9 & 1.1 & 0.08 \\
\hline $\mathrm{H}: \mathrm{L}$ ratio & $0.35^{\mathrm{a}}$ & $0.32^{\mathrm{b}}$ & $0.30^{\mathrm{b}}$ & $0.31^{\mathrm{b}}$ & 0.02 & 0.02 \\
\hline
\end{tabular}

\section{Results}

The results indicated that BWG, ADG, and FCR responded markedly to MOS or MOS + CXEO supplementation of the CON diet (Table 2). Compared with the CON group, the BWG and ADG of the MOS group were increased $(P<0.05)$ by 4.9 and $7.9 \%$, respectively. Also, when both MOS and CXEO were supplemented in combination, BWG and ADG were significantly increased $(P<0.05)$ by 5.4 and $8.6 \%$, respectively, compared to the CON. Dietary treatments did not affect ADFI during the finisher phase of the experiment. Dietary supplementation of MOS and MOS + CXEO significantly improved FCR $(P<0.05)$ by 6.8 and $7.3 \%$, respectively, when compared with the nonsupplemented group.

Effects of the dietary MOS and CXEO supplementations on relative visceral-organ weight are shown in Table 3. With regard to relative organ weight, there were no differences for variables, except for the spleen value, which was higher for the birds fed the MOS than those fed CON diet $(P<0.05)$.

It was noted that all MOS- and CXEO-supplemented groups significantly decreased $(P<0.05)$ the $\mathrm{H}: \mathrm{L}$ ratio and
CS concentrations of broilers (Table 4) in comparison with the $\mathrm{CON}$ group. This decrease in $\mathrm{H}: \mathrm{L}$ ratio as a result of the dietary treatments was recorded in the MOS (8.6\%), CXEO $(14.3 \%)$, and MOS + CXEO $(11.4 \%)$ groups. The results indicated that $\mathrm{CHO}, \mathrm{L}$, and $\mathrm{H}$ levels were statistically nonsignificant. A significant decrease $(P<0.05)$ was found in the CK activity of breast muscle for the dietary treatments as compared with the CON group (Fig. 1). Real-time PCR analysis showed that dietary treatments downregulated the HSP7O gene expression in breast muscle (Fig. 2a) and jejunum (Fig. 2b) with a significant difference $(P<0.05)$ compared with the CON group.

Regarding the duodenal morphology, dietary treatments did not have a significant effect on the duodenum criteria measured (Table 5). There were significant differences between treatments for jejunum morphometry. In birds fed with MOS and MOS + CXEO, villus length, crypt depth, and villus-length-to-crypt-depth ratio in the jejunum were increased $(P<0.05)$ compared to those fed CON and CXEO diets. 
Table 5. Effect of mannan oligosaccharide (MOS) and Curcuma xanthorrhiza essential oil (CXEO) on intestinal morphometry in broilers subjected to heat challenge.

\begin{tabular}{|c|c|c|c|c|c|c|}
\hline \multirow[t]{2}{*}{ Item } & \multicolumn{4}{|c|}{ Treatments $^{1}$} & \multirow[t]{2}{*}{ SEM } & \multirow[t]{2}{*}{$P$ value } \\
\hline & Control & MOS & CXEO & $\mathrm{MOS}+\mathrm{CXEO}$ & & \\
\hline \multicolumn{7}{|l|}{ Duodenum } \\
\hline Villus length $(\mu \mathrm{m})$ & 1356 & 1361 & 1353 & 1359 & 1.40 & 0.13 \\
\hline Crypt depth $(\mu \mathrm{m})$ & 187 & 189 & 188 & 185 & 0.53 & 0.11 \\
\hline Ratio & 7.25 & 7.20 & 7.19 & 7.27 & 0.12 & 0.45 \\
\hline \multicolumn{7}{|l|}{ Jejunum } \\
\hline Villus length $(\mu \mathrm{m})$ & $1165^{\mathrm{b}}$ & $1228^{a}$ & $1171^{\mathrm{b}}$ & $1230^{\mathrm{a}}$ & 1.6 & 0.04 \\
\hline Crypt depth $(\mu \mathrm{m})$ & $154^{\mathrm{b}}$ & $160^{\mathrm{a}}$ & $156^{\mathrm{b}}$ & $161^{\mathrm{a}}$ & 1.1 & 0.02 \\
\hline Ratio & $7.56^{\mathrm{b}}$ & $7.68^{\mathrm{a}}$ & $7.51^{\mathrm{b}}$ & $7.64^{\mathrm{a}}$ & 0.05 & 0.03 \\
\hline
\end{tabular}

a-b Mean values within a line with no common superscript differ significantly from each other $(P<0.05)$. Each value represents the mean of 12 observations (six replicates $\times$ two birds / replicate). ${ }^{1}$ The control group was fed no additive. Other groups were fed $5 \mathrm{~g} \mathrm{~kg}^{-1}$ of MOS (MOS), $400 \mathrm{mg} \mathrm{kg}^{-1}$ of CXEO (CXEO), or $5 \mathrm{~g} \mathrm{~kg}^{-1}$ of MOS $+400 \mathrm{mg} \mathrm{kg}^{-1}$ of CXEO (MOS + CXEO).

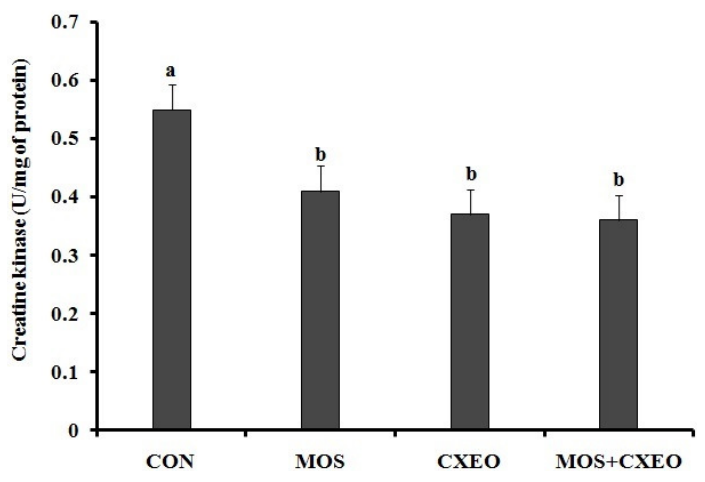

Figure 1. Effect of mannan oligosaccharide (MOS) and Curcuma xanthorrhiza essential oil (CXEO) on creatine kinase (expressed as $\mathrm{Umg}^{-1}$ of protein) level of chicken breast muscle. Mean values represent the average of 12 observations (six replicates $\times$ two birds / replicate). Values are means \pm SEM. Within the graph, bars with different letters $(\mathrm{a}, \mathrm{b})$ are significantly different $(P<0.05)$. $\mathrm{CON}$ : control group fed no additive. Other groups were fed $5 \mathrm{~g} \mathrm{~kg}^{-1}$ of MOS (MOS), $400 \mathrm{mg} \mathrm{kg}^{-1}$ of CXEO (CXEO), or $5 \mathrm{~g} \mathrm{~kg}^{-1}$ of $\mathrm{MOS}+400 \mathrm{mg} \mathrm{kg}^{-1}$ of CXEO (MOS + CXEO).

\section{Discussion}

This study was planned to evaluate the effects of MOS and CXEO supplementations on broiler performance when reared under cyclic HS. Results indicated that MOS and MOS + CXEO treatments increased growth performance of birds exposed to cyclic HS. Silva et al. (2009) observed that feeding MOS can improved BWG and lower FCR, similar to the current study. Based on a review of the literature, there are inconsistent results in some studies on the effects of MOS supplementation on the productive performance of broilers. In some MOS supplementation reports there were improvements in performance (Chee et al., 2010; Sohail et al., 2012), while in other studies there were no positive effects of MOS-supplemented diets (Baurhoo et al., 2009; Alzueta et al., 2010). Environmental condition, nutrition, sex, strain, stage of production, and dosage can have an effect on the response of broilers to the inclusion of MOS (Yang et al., 2009) and thus account for the contradictory results. It has been suggested that MOS has more beneficial effects under suboptimal experimental conditions (Sohail et al., 2012). It has been found that birds fed diets supplemented with MOS had better growth performance than the unsupplemented group under disease or HS, whereas under conditions of mild stress, the control and MOS groups had insignificant results regarding broiler BW, feed intake, and FCR (MoralesLopez et al., 2009; Baurhoo et al., 2009). Morales-Lopez et al. (2009) and Baurhoo et al. (2009) concluded that the absence of any significant effect might be associated with the lack of a real challenge. Hence, it seems that dietary supplementation with MOS has more advantages when birds are reared under cyclic HS condition. Oligosaccharides improve appetite and increase feed intake in broiler chickens, which finally increase feed efficiency. Also, it is believed that high temperature reduces feed intake (Sohail et al., 2012). In this study, dietary treatments could not promote the consumption of more feed. The insignificant effects of CXEO observed in the present research can be due to several reasons, consisting of either inappropriate doses used or HS condition.

It seems that low feed consumption of broilers exposed to cyclic HS resulted in the delayed development of certain viscera. The relative lymphoid organ weight was used to judge the immunity of birds. Investigating the HS on the bursa of broilers shows that stress induces lymphoid organ atrophy and a reduction in relative bursa weight (QuinteiroFilho et al., 2010). The findings of the present study agree 

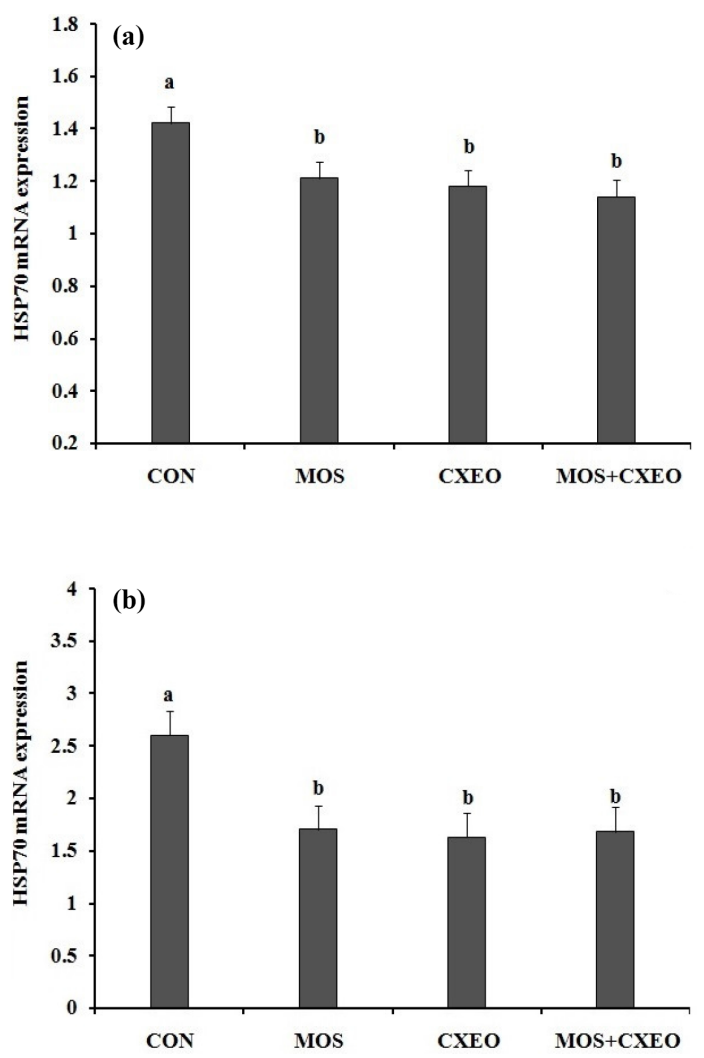

Figure 2. Effect of mannan oligosaccharide (MOS) and Curcuma xanthorrhiza essential oil (CXEO) on relative values of HSP70 mRNA expression in chicken breast muscle (a) and jejunum (b). Mean values represent the average of 12 observations (six replicates $\times$ two birds / replicate). Values are means \pm SEM. Within the graph, bars with different letters $(\mathbf{a}, \mathbf{b})$ are significantly different $(P<0.05)$. CON: control group fed no additive. Other groups were fed $5 \mathrm{~g} \mathrm{~kg}^{-1}$ of MOS (MOS), $400 \mathrm{mg} \mathrm{kg}^{-1}$ of CXEO (CXEO), or $5 \mathrm{~g} \mathrm{~kg}^{-1}$ of MOS $+400 \mathrm{mg} \mathrm{kg}^{-1}$ of CXEO (MOS + CXEO).

with data reported by Quinteiro-Filho et al. (2010), who indicated a glucocorticoid-dependent mechanism responsible for lymphoid organ involution under HS. The increase in relative bursa weight in the MOS-supplemented group may be a result of the immune-booster effects of prebiotics, as in the present results.

It is well documented that environmental stressors (such as HS) can increase plasma CS concentration and levels of HSP7O in different tissues of poultry with a concomitant increase in circulating $\mathrm{H}: \mathrm{L}$ ratio and $\mathrm{CK}$ level (Garriga et al., 2006). The results of the present study indicate that HS biomarkers were modulated by dietary treatments, which are probably an indication of the improving effects of MOS and CXEO under heat challenge. In other words, the resistance to high ambient temperature was improved in the broilers fed MOS and CXEO, as evidenced by lower HSP70 gene expression. These results are consistent with the findings of Sohail et al. (2010) and Akbarian et al. (2013), who reported that supplementation with MOS and CXEO decreased the negative effects of HS. Based on these results it can be concluded that the supplementation with MOS or CXEO alone and in combination had protective effects against the onset of oxidative damage. A strong relationship between the synthesis of HSP70 and oxidation in stressed cells has been detected (Akbarian et al., 2013).

In this study, there were no significant differences between CON and CXEO groups for morphometric indices. It is hypothesized that the overall effect of essential oils on gut morphology related to the balance between tissue inflammation and beneficial effects on intestinal health (Yamauchi et al., 1996). In other words, HS is associated with intestinal irritation. The results of the present research could be explained by selected doses for CXEO not being able to improve morphometric indices that might be negatively affected by HS and exert a positive effect on intestinal morphology. Increases in villus length and crypt depth provide a greater surface area for the digestion and absorption of nutrients subsequent to an increase in mucosal enzymes, absorption, and the nutrient transport system (Sohail et al., 2012). In the current study, the inclusion of MOS improved histomorphological parameters of the intestinal jejunum segment. The present results are in agreement with findings of Sohail et al. (2012), who reported that MOS has positive effects on intestinal morphology. The improvement in intestinal histology could probably be the overall effect of MOS fed to heat-stress-challenged broilers.

\section{Conclusions}

It was concluded that the dietary use of CXEO as a feed additive may be a practical nutritional strategy for broilers during the finisher phase to overcome or reduce the disadvantageous effects of cyclic HS in broiler production. Based on these findings, it was also concluded that the dietary supplementation of MOS can help in decreasing harmful effects of HS in broiler chickens.

Acknowledgements. This work was financially supported by the University of Birjand, Iran.

Edited by: M. Mielenz

Reviewed by: two anonymous referees

\section{References}

Akbarian, A., Golian, A., Kermanshahi, H., Raji, A. R., Farhoosh, R., De Smet, S., and Michiels, J.: Growth performance and gut health parameters of finishing broilers supplemented with plant extracts and exposed to daily increased temperature, Span. J. Agric. Res., 11, 109-119, 2013.

Akbarian, A., Michiels, J., Golian, A., Buyse, J., Wang, Y., and De Smet, S.: Gene expression of heat shock protein 70 and antioxidant enzymes, oxidative status, and meat oxidative stability of 
cyclically heat-challenged finishing broilers fed Origanum compactum and Curcuma xanthorrhiza essential oils, Poult Sci., 93, 1930-1941, 2014.

Alzueta, C., Rodriguez, M. L., Ortiz, L. T., Rebole, A., and Trevino, J.: Effects of inulin on growth performance, nutrient digestibility and metabolisable energy in broiler chickens, Br. Poult. Sci., 51, 393-398, 2010.

Aviagen ${ }^{\circledR}$ : Ross 308 broiler management guide, 2011.

Avila-Ramos, F., Pro-Martinez, A., Sosa-Montes, E., Cuca-Garcia, J. M., Becerril-Perez, C. M., Figueroa-Velasco, J. L., and Narciso-Gaytan, C.: Effects of dietary oregano essential oil and vitamin $\mathrm{E}$ on the lipid oxidation stability of cooked chicken breast meat, Poult. Sci., 91, 505-511, 2012.

Baurhoo, B., Ferket, P. R., and Zhao X.: Effects of diets containing different concentrations of mannanoligosaccharide or antibiotics on growth performance, intestinal development, cecal and litter microbial populations, and carcass parameters of broilers, Poult. Sci., 88, 2262-2272, 2009.

Buijs, S., Keeling, L., Rettenbacher, S., Van Poucke, E., and Tuyttens, F. A. M.: Stocking density effects on broiler welfare: Identifying sensitive ranges for different indicators, Poult. Sci., 88, 1536-1543, 2009.

Chee, S. H., Iji, P. A., Choct, M., Mikkelsen, L. L., and Kocher, A.: Characterisation and response of intestinal microflora and mucins to manno-oligosaccharide and antibiotic supplementation in broiler chickens, Br. Poult. Sci., 51, 368-380, 2010.

De Jong, I. C., van Voorst, A., Erkens, J. H. F., Ehlhardt, D. A., and Blokhuis, H. J.: Determination of the circadian rhythm in plasma corticosterone and catecholamine concentrations in growing broiler breeders using intravenous cannulation, Physiol. Behav., 74, 299-304, 2001.

Garriga, C., Hunter, R. R., Amat, C., Planas, J. M., Mitchell, M. A., and Moreto, M.: Heat stress increases apical glucose transport in the chicken jejunum, Am. J. Physiol. Regul. Integr. Comp. Physiol., 290, R195-R201, 2006.

Ghareeb, K., Awad, W. A., Nitsch, S., Abdel-Raheem, S., and Bohm, J.: Effects of transportation on stress and fear responses of growing broilers supplemented with prebiotic or probiotic, Int. J. Poult. Sci., 7, 678-685, 2008.

Hao, Y., Gu, X. H., and Wang, X. L.: Overexpression of heat shock protein 70 and its relationship to intestine under acute heat stress in broilers: 1. Intestinal structure and digestive function, Poult. Sci., 91, 781-789, 2012

Luna, A., Labaque, M. C., Zygadlo, J. A., and Marin R. H.: Effects of thymol and carvacrol feed supplementation on lipid oxidation in broiler meat, Poult. Sci., 89, 366-370, 2010.

May, J. D., Deaton, J. W., Reece, F. N., and Branton, S. L.: Effect of acclimation and heat stress on thyroid hormone concentration, Poult. Sci., 65, 1211-1213, 1986.
Morales-Lopez, R., Auclair, E., Garcia, F., Esteve-Garcia, E., and Brufau, J.: Use of yeast cell walls; $\beta$-1, 3/1, 6-glucans; and mannoproteins in broiler chicken diets, Poult. Sci., 88, 601-607, 2009.

Patterson, J. A. and Burkholder, K. M.: Application of prebiotics and probiotics in poultry production, Poult. Sci., 82, 627-631, 2003.

Quinteiro-Filho, W. M., Ribeiro, A., Ferraz-de-Paula, V., Pinheiro, M. L., Sakai, M., Sa, L. R., Ferreira, A. J., and Palermo-Neto, J.: Heat stress impairs performance parameters, induces intestinal injury, and decreases macrophage activity in broiler chickens, Poult. Sci., 89, 1905-1914, 2010.

Silva, V. K., Della Torre da Silva, J., Torres, K. A. A., de Faria Filho, D. E., Hirota Hada, F., and Barbosa de Moraes, V. M.: Humoral immune response of broilers fed diets containing yeast extract and prebiotics in the prestarter phase and raised at different temperatures, J. Appl. Poult. Res., 18, 530-540, 2009.

Sohail, M. U., Ijaz, A. M., Yousaf, S., Ashraf, K., Zaneb, H., Aleem, M., and Rehman H.: Alleviation of cyclic heat stress in broilers by dietary supplementation of mannan-oligosaccharide and Lactobacillus-based probiotic: Dynamics of cortisol, thyroid hormones, cholesterol, C-reactive protein, and humoral immunity, Poult. Sci., 89, 1934-1938, 2010.

Sohail, M. U, Hume, M. E., Byrd, J. A., Nisbet, D. J., Ijaz, A., Sohail, A., Shabbir, M. Z., and Rehman, H.: Effect of supplementation of prebiotic mannan-oligosaccharides and probiotic mixture on growth performance of broilers subjected to chronic heat stress, Poult. Sci., 91, 2235-2240, 2012.

Yahav, S., Goldfeld, S., Plavnik, I., and Hurwitz, S.: Physiological responses of chickens and turkeys to relative humidity during exposure to high ambient temperature, J. Therm. Biol., 20, 245253, 1995.

Yang, Y., Iji, P. A., and Choct, M.: Dietary modulation of gut microflora in broiler chickens: A review of the role of six kinds of alternatives to in-feed antibiotics, World's Poult. Sci. J., 65, 97114, 2009.

Yamauchi, K., Kamisoyama, H., and Isshiki, Y.: Effects of fasting and refeeding on structures of the intestinal villi and epithelial cells in White Leghorn hens, Br. Poult. Sci., 37, 909-921, 1996.

Zhang, J. J., Piao, X. S., Huang, D. S., Wang, J. J., Ma, X., and Ma, Y. X.: Effects of feed particle size and feed form on growth performance, nutrient metabolizability, and intestinal morphology in broiler chickens. Asian-australas, J. Anim. Sci., 22, 107-112, 2009. 